Conclusions In summary, our study demonstrates that laboratory animal workers carry out animal allergen on their skin when they leave the animal facility at the end of the day. The implication of these findings will be considered in the development of safe working practices in prevention of laboratory animal allergy within the context of the SPIRAL study.

\section{P59 TO DETERMINE MUS M 1 PERSONAL EXPOSURE IN LABORATORY ANIMAL WORKERS IN FACILITIES WHERE MICE ARE HOUSED IN OPEN CAGES AND INDIVIDUALLY VENTILATED CAGES}

IJ Canizales, ${ }^{2} \mathrm{M}$ Jones, ${ }^{3} \mathrm{~S}$ Semple, ${ }^{1} \mathrm{~J}$ Feary, ${ }^{2} \mathrm{P}$ Cullinan. ${ }^{1}$ Royal Brompton and Harefield NHS Foundation Trust, London, UK; ${ }^{2}$ Imperial College, London, UK; ${ }^{3}$ University of Aberdeen, Aberdeen, UK

\subsection{6/thoraxjn-2015-207770.196}

Background Laboratory animal workers face the risk of developing an IgE-associated respiratory allergy to airborne proteins, such as Mus $\mathrm{m} 1$ (mouse urinary protein). Approximately 15\% of exposed employees will develop IgE sensitisation and 10\% clinically apparent disease. We have recently embarked on a large study called SPIRAL (Safe Practice In Reduction of Allergy in Laboratories) to gain a greater understanding of laboratory animal allergy (LAA) and to determine whether we can devise a code of safe practice to prevent, as far as possible, the future occurrence of LAA.

Aim To determine personal exposure to Mus m 1 within animal facilities where mice are housed exclusively in open cages and exclusively in individually ventilated cages (IVC).

Methods Selected employees wore Casella Apex pumps (2 L/ $\mathrm{min}$ ) during their full shifts to collect inhalable particulate onto fluoropore membrane $(1 \mu \mathrm{m}), 25 \mathrm{~mm}$ filters using IOM sampling heads. 82 filters from an IVC facility and 56 filters from an open cage facility were analysed for Mus $\mathrm{m} 1$ using a commercial sandwich enzyme linked immunoassay (Indoor Biotechnology).

Results The range of Mus $\mathrm{m} 1$ levels within the IVC facility was $0.00-66.33 \mathrm{ng} / \mathrm{m}^{3}$ and in the open cage facility was 3.89-305.59 $\mathrm{ng} / \mathrm{m}^{3} .11(13 \%)$ of samples from the IVC facility and $50(89 \%)$ of samples from the open cage facility had a Mus $\mathrm{m} 1$ exposure level greater than $5 \mathrm{ng} / \mathrm{m}^{3}$. Additionally, there was substantial variation when task specific sampling was carried out over short periods of time compared with full shift sampling. Further analyses will allow us to identify which tasks were associated with highest levels of exposures.

Conclusions The majority of samples from the open cage facility were above $5 \mathrm{ng} / \mathrm{m}^{3}$, a figure previously suggested to limit or reduce incidence of LAA. Although use of IVCs has been shown to reduce exposure to Mus $\mathrm{m}$ 1, we found several samples above $5 \mathrm{ng} / \mathrm{m}^{3}$. Exposure to high allergen levels will be influenced by cage type, variation in individual working practices and carrying out of specific "high-risk" tasks; some of these factors may be modifiable and these results may be used to change practice.

\section{P60 UPTAKE AND QUALITY OF HEALTH SURVEILLANCE FOR OCCUPATIONAL ASTHMA IN THE UK}

${ }^{1} \mathrm{D}$ Fishwick, ${ }^{2} \mathrm{D}$ Sen, ${ }^{2} \mathrm{P}$ Barker, ${ }^{1} \mathrm{~A}$ Codling, ${ }^{1} \mathrm{D}$ Fox, ${ }^{1} \mathrm{~S}$ Naylor. ${ }^{1}$ Centre for Workplace Health, Buxton, UK; ${ }^{2} H S E$, Bootle, UK

10.1136/thoraxjnl-2015-207770.197
Introduction Statutory periodic health surveillance (HS) of workers can identify early cases of occupational asthma. Information about its uptake in the UK, and its content when carried out, are lacking.

Methods A telephone survey of employers, and their occupational health professionals, was carried out in three sectors with the potential for producing exposures, which may result in the development of occupational asthma (bakeries, wood working, motor vehicle repair).

Results 457 organisations participated (31\% response rate); 77\% employed less than 10 people, $17 \%$ between 10 and 50 and $6 \%$ more than 50. Risk assessments were common (67\%) and 14\% carried out any form of occupational asthma HS, rising to $19 \%$ if only organisations reporting asthma hazards and risks were considered. HS was carried out by both in-house (31\%) and external providers (69\%). Organisational policies were often used to define surveillance approaches (80\%), but shared with the occupational health provider only in one third of cases.

Occupational health providers described considerable variation in practice, with differing approaches seen for information sharing and workplace visits. Record keeping was universal, but worker-held records were not reported. Health surveillance tools, such as a questionnaire, were generally developed inhouse. Lung function was commonly measured, but only limited interpretation was evident. The referral of workers to local specialist respiratory services was variable.

Conclusions This study has provided new insights into the real world of health surveillance for occupational asthma in the UK. We consider that future work could and should define more practical, evidence based and simple approaches to HS, by working with the end users to develop interventions that meet their needs. This will ensure maximal uptake of high quality HS approaches and consistency.

\section{P61 RESPIRATORY ILL HEALTH IN THE SILICA EXPOSED BRICK MANUFACTURING SECTOR}

D Fishwick, J Sumner, CM Barber, E Robinson, A Codling, L Lewis, C Young, N Warren. Centre for Workplace Health, HSL, Buxton, UK

\subsection{6/thoraxinl-2015-207770.198}

Introduction Exposure at work to inhaled respirable crystalline silica (RCS) has previously been linked with silicosis, tuberculosis, lung cancer and COPD. Whilst the risk of developing silicosis is largely a function of cumulative lifetime RCS exposures, current workplace exposures contribute to this risk.

Methods A cross sectional GB based workplace study of brick manufacturers was carried out, in order to identify a subsequent longitudinal cohort. Participating worksites were using silica to make bricks for various uses. Consenting workers were asked to complete an interviewer led questionnaire, undergo lung function testing and complete a full occupational history including details of lifetime exposure to RCS. Consenting workers had a PA Chest Radiograph using a mobile facility, and levels of RCS exposure in the personal breathing zone were taken.

Results 189 workers took part, with a mean age of 45.9 years and 22 years median (range $0.08-47$ ) years worked overall in industry. Three had radiological evidence of silicosis (ILO standards used; 2 definite and one probable case). Respiratory symptoms were common; for example $14.3 \%$ reported cough, $21.2 \%$ wheeze in the last 12 months, $14.3 \%$ reported ever having asthma. $13.2 \%$ reported at least one work related respiratory 